ISSN 2236-0859

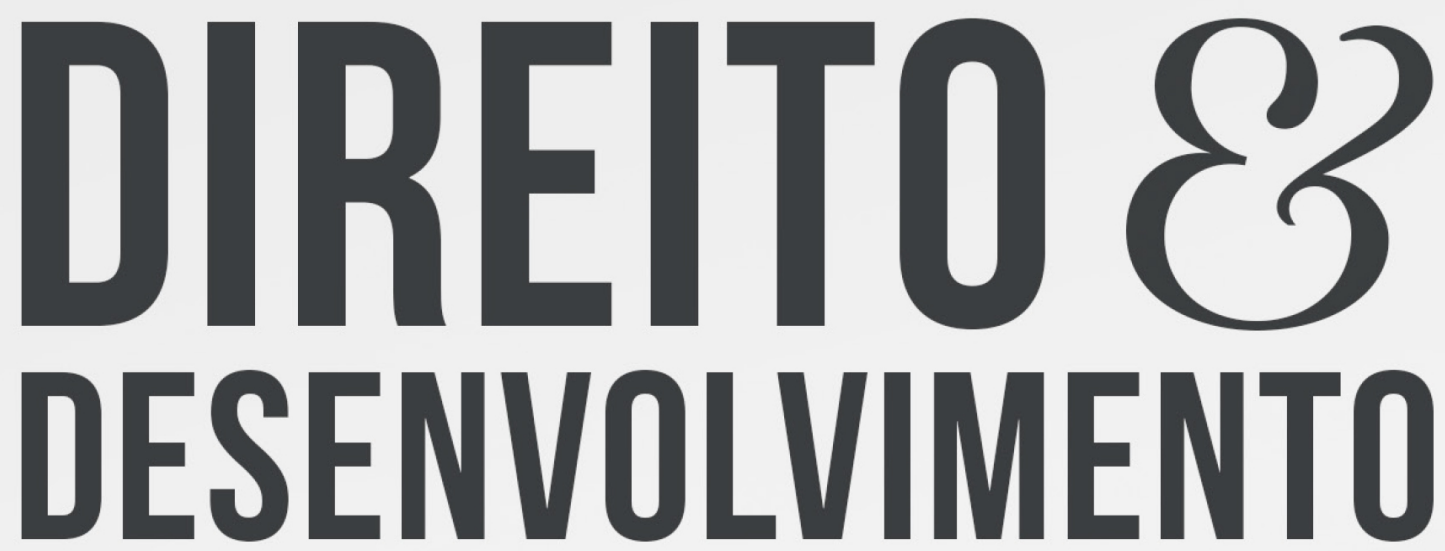

REVISTA DO PROGRAMA DE PÓS-GRADUAÇ̃̃O EM DIREITO MESTRADO EM DIREITO E DESENVOLVIMENTO SUSTENTÁVEL

CREDIT SCORING E A PROTEÇÃO DE DADOS PESSOAIS

MARILIA DE MORAES PERES

ADALBERTO SIMÃO FILHO 


\title{
CREDIT SCORING E A PROTEÇÃO DE DADOS PESSOAIS
}

\section{CREDIT SCORING AND THE PROTECTION OF PERSONAL DATA}

Recebido: 14/02/2020

Aprovado: 19/05/2021

Marilia de Moraes Peres ${ }^{1}$

Adalberto Simão Filho

\section{RESUMO:}

O avanço da tecnologia propiciou o uso de métodos de tratamento de dados, incorporando, no dia a dia de determinadas empresas, filtros que permitem minuciar o usuário. Mas essa utilização indiscriminada vem sendo limitada em vários países do globo, fazendo com que o emprego do tratamento de dados seja adequado às recentes normas. No Brasil, foi sancionada a Lei no 13.709, em 14 de agosto de 2018 (LGPD), que entrará em vigência em dezembro de 2020, obrigando as companhias nacionais a fazer os devidos ajustes conforme as exigências legais. As instituições financeiras, normalmente, utilizam o procedimento do credit scoring para auferir pontuação adequada a cada perfil de solicitante de crédito, sendo que esse sistema requer o emprego de dados. Com a implantação da nova legislação, haverá um impacto sobre o setor do crédito. Todavia, este impacto será diminuto, porém essencial tanto para a liberdade individual quanto para a saúde econômica do país.

Palavras-chave: Finanças. Intermediação Financeira. Estados em desenvolvimento.

\begin{abstract}
:
The advancement of technology has enabled the use of data processing methods, incorporating, in the daily lives of certain companies, filters that allow the user to be detailed. But such indiscriminate use has been limited in many countries around the globe, making the use of data processing appropriate to recent standards. In Brazil, Law No. 13,709 was approved on August 14, 2018 (LGPD), which will become effective in December 2020, forcing domestic companies to make appropriate adjustments in accordance with legal requirements. Financial institutions usually use the credit scoring procedure to obtain an appropriate score for each credit applicant profile, this system requires the use of data. With the implementation of the new legislation, there will be an impact on the credit sector, but it will be small but essential for the individual freedom and economic health of the country.
\end{abstract}

Keywords: Finance. Financial Intermediation. Developing States.

\footnotetext{
1 Possui graduação em Direito pela Universidade Paulista (2017). Tem experiência na área de Direito, com ênfase em Direito. Mestre em Direito Coletivos e Cidadania da Universidade de Ribeirão Preto - UNAERP, em 2020, sob a orientação do Prof. Dr. Rafael Tomaz de Oliveira no período de 2018 a 2020. Bolsista Prosup/CAPES. Participante do Grupo de Estudos: "Justiça Política e Cidadania". Email: md.peres@uol.com.br

2 Possui graduação em Direito pela Faculdades Metropolitanas Unidas (1981), mestrado em Direito das Relações Sociais pela Pontifícia Universidade Católica de São Paulo (1991), doutorado em Direito das Relações Sociais pela Pontifícia Universidade Católica de São Paulo (2002) e Pós-Doutor pela Universidade de Coimbra (2009-2011). Atualmenteé docente titular da Universidade de Ribeirão PretoUNAERP, no Programa de Pós-Graduação em Direitos Coletivos e Cidadania, níveis doutorado e mestrado. Professor do programa de pós graduação em direito comercial da COGEAE/PUC-SP. Diretor do Escritório de Advocacia Simão Filho Advogados. Tem experiência em Direito Empresarial, atuando principalmente nos seguintes temas: Direito tecnológico, inovação e proteção de dados, Direitos coletivos, Consumidor e interesses difusos, soluções éticas de conflito, negociações e automediação. Membro Fundador do Instituto Brasileiro de Direito Contratual (IBDCont) e do Instituto Avançado de Proteção de Dados (IAPD). Email: adalbertosimao@uol.com.br
} 


\section{INTRODUÇÃO}

Em maio de 2018, o General Data Protection Regulation (GDPR) entrou em vigor no continente europeu. Com a nova legislação, o tratamento de dados pessoais passou a ser regulado vinculando todos os cidadãos europeus e empresas, envolvidas no tratamento de dados, com base em algum dos países da União Europeia. A disposição do artigo $3^{\circ}$ da $G D P R$, possui aplicação territorial estendida, uma vez que o mesmo se refere ao "tratamento de dados pessoais efetuados no contexto das atividades de um estabelecimento de um responsável pelo tratamento ou de um subcontratante situado no território da União, independentemente de o tratamento ocorrer dentro ou fora da União".

Essa aplicação territorial acaba abarcando empresas da União, mesmo que faça tratamento de dados de estrangeiros; ou seja, companhias de fora da União que trabalhem com informações de cidadãos europeus ou não que se encontrem em território europeu.

Outro dispositivo que vincula empresas de fora da União Europeia se encontra no capítulo V, do GDPR. Esse capítulo trata da "transferência de dados pessoais para países terceiros ou organizações internacionais”. Assim, a transferência só será possível se as condições do regulamento forem respeitadas, tanto pelo responsável no que se refere ao tratamento quanto pelo subcontratante. Para tanto, haverá uma "decisão de adequação", à qual só será possível se puderem ser observados os direitos humanos e as liberdades fundamentais, assim como a legislação pertinente em vigor, entre outros insertos no artigo $45^{\circ}$ do Regulamento GDPR.

O território de aplicação e os dispositivos do artigo 45, provocam reflexos em empresas de todo o planeta, inclusive no Brasil.

Essa situação aliada à aspiração do Brasil na entrada do país na OCDE (Organização para a Cooperação e Desenvolvimento Econômico), representa a organização que possui uma diretriz sobre a proteção da privacidade e fluxos transfronteiriços de dados pessoais ${ }^{3}$, acarretando uma mudança na legislação pátria e, em 14 de agosto de 2018, a Lei oㅡ 13.709 foi sancionada. Para que as empresas nacionais e estrangeiras, com negócios no Brasil, possam se adaptar, a referida Lei entrará em vigor após 24 meses de sua publicação, sendo em 2020 o início de sua vigência.

A entrada em vigor dessa legislação tem mexido com vários setores da economia, dentre eles o próprio sistema financeiro e a coleta de dados com fins bancários.

Com foco nos assuntos acima abordados, o presente artigo visa explorar como a Lei de Proteção de dados pessoais brasileira (LGPD) tem impactado o setor das informações pessoais e a concessão de crédito no Brasil. Será feito ainda uma breve explanação sobre a lei nacional, além de investigarmos o sistema de crédito, o funcionamento do credit scoring bancário e o cadastro positivo. Por fim, analisaremos a consequência da influência da nova legislação neste setor.

Essa pesquisa é bibliográfica-exploratória construída através do método hipotéticodedutivo. Foi realizada com fomento da bolsa de estudo PROSUP/CAPES.

\section{A LEI GERAL DE PROTEÇÃO DE DADOS PESSOAIS - LEI № 13.709 DE 14 DE AGOSTO DE 2018}

A preocupação com os dados pessoais surgiu porque, atualmente, muitos fatores do nosso dia a dia se relacionam com tais dados sensíveis. Redes sociais, bancos, empresas de marketing, entre outros, capturam nossas informações a cada acesso e os tratam, armazenando

3 OECD Guidelines on the Protection of Privacy and Transborder Flows of Personal Data. 
em um grande banco de dados quais são os nossos gostos, preferências, estilos de vida, e outros aspectos. Essas informações, de forma estruturada, acabam possuindo um valor econômico, tanto para a utilização dentro da própria empresa como para a sua comercialização e, muitas vezes sem respeitar a privacidade do cidadão.

E é exatamente a forma de estruturação da base de dados de maneira que a mesma possa ser eficientemente pesquisada e esta potencialidade de multiutilização para fins diversos como o econômico, que acaba por gerar um valor que não se coaduna em muitos casos, com a necessidade de proteção da privacidade do cidadão. (SIMÃO; SCHWARTZ, 2016, p. 8)

O tratamento de dados, além de ser utilizado em âmbito meramente comercial de marketing ou publicitário, tem impactado outras esferas, como por exemplo a da política. Inclinações políticas expostas em redes sociais, devidamente tratadas, ocasionaram um dos maiores escândalos envolvendo informações pessoais. A empresa Cambridge Analytica do grupo inglês SCL (Strategic Communication Laboratories), analisou dados de 50 milhões de pessoas contidos na rede social facebook, o que influenciou, através de uma campanha bem arquitetada, a eleição do presidente norte-americano Donald Trump. O caso não termina por aí. Segundo o jornal O Globo (2018), o delator Christopher Wylie expôs que a empresa Cambridge Analytica participou de mais de 200 eleições pelo mundo.

Fora da esfera política, a questão não se torna diferente. Governos e empresas privadas têm utilizado informações para tirar grandes vantagens. Continuamente o direito à privacidade vem sendo violado com o total desconhecimento do usuário. Desse modo, em um universo de transmissão e coleta de dados, foi necessário repensar a privacidade. É neste contexto que se encontra o pensamento de Doneda (2016, p.14):

(...) a proteção da privacidade na sociedade da informação, tomada na sua forma de proteção de dados pessoais, avança sobre terrenos outrora intransponíveis e nos induz a pensá-la como um elemento que, antes de garantir o isolamento ou a tranquilidade, serve a proporcionar ao indivíduo meios necessários à construção e consolidação de uma esfera privada própria, dentro de um paradigma de vida em relação e sob o signo da solidariedade.

Essa construção de uma esfera privada dentro dos moldes dos meios eletrônicos, em conjunto com uma série de riscos à harmonia da democracia, obrigou o poder público a buscar meios de maior proteção na coleta e no tratamento dos dados pessoais. Após a adoção do Regulamento da União Europeia para a proteção das informações pessoais (GDPR), o Brasil rumou no mesmo sentido. A Lei Geral de Proteção de Dados Pessoais brasileira (LGPD) segue os moldes da GDPR. Sua área de atuação está no uso indevido, comercialização e vazamento de dados pessoais.

A nova lei tem uma profunda preocupação com a privacidade, trazendo-a tanto como objetivo, no artigo $1^{\circ}$ que aduz "proteger os direitos fundamentais de liberdade e de privacidade e o livre desenvolvimento da personalidade da pessoa natural.", quanto como perspectiva, sendo o primeiro fundamento exposto em seu artigo $2^{\mathrm{o}} .4$

Assim como a GDPR, a LGPD possui um território de atuação estendido. Contempla qualquer operação de tratamento de dados pessoais por pessoas ou empresas, públicas ou privadas, quando a coleta ou as operações forem executadas no território nacional ou que contenham por objetivo oferta ou fornecimento de bens, serviços ou o próprio tratamento de informações de pessoas localizadas no Brasil. Desse modo, mesmo que as companhias não estejam localizadas fisicamente no país não poderão atuar sem observar os preceitos legais. Da mesma forma, quando o indivíduo nacional ou estrangeiro estiver nesse território, não poderá

4 BRASIL, Lei 13.709 de 14 de agosto de 2018. Art. $2^{\text {o }}$ - A disciplina da proteção de dados pessoais tem como fundamentos: I - o respeito à privacidade. 
ter seus dados tratados sem a observância legal. Tal dispositivo se coaduna com o artigo $3^{\circ}$, do Regulamento europeu mantendo uma sincronia com o mesmo.

Contudo, o artigo $4^{\circ}$, da lei brasileira, traz uma série de exceções, permitindo que o tratamento de dados sejam feitos: por pessoa natural com fins particulares e não lucrativos; para finalidades exclusivamente jornalísticas, artísticas ou acadêmicas; de segurança ou defesa nacional; segurança do Estado; atividades de investigação e repressão de infrações penais; ou provenientes de fora do território nacional e que não sejam objeto de comunicação, uso compartilhado de informações com agentes de tratamento brasileiros ou objeto de transferência internacional de dados com outro país que não o de proveniência, desde que o país de proveniência proporcione grau de proteção de dados pessoais adequado ao previsto nesta Lei5.

A referida Lei diferencia os dados e considera dado pessoal uma informação que se relaciona à pessoa natural identificada ou identificável, podendo ser qualquer tipo de informação como nome, endereço, e sendo também através de uma informação processada como o endereço de e-mail corporativo ligando a pessoa a uma determinada empresa. Acrescenta-se ainda o dado pessoal sensível como são os ligados à personalidade, como por exemplo, a religião, a etnia, a opinião política, além das informações referentes à saúde ou à vida sexual, entre outros. E há o dado anonimizado que são aquelas informações relativas a uma pessoa "que não possa ser identificada, considerando a utilização de meios técnicos razoáveis e disponíveis na ocasião de seu tratamento."

A Lei contempla, ainda, outras definições como banco de dados, titular, controlador, operador, encarregado, agentes de tratamento, tratamento, entre outros. ${ }^{7}$

Dentre os princípios do artigo 6º, destacam-se a finalidade, a adequação, necessidade, livre acesso, a qualidade dos dados, a transparência, segurança, prevenção, não discriminação e a responsabilização com prestação de contas.

Um dos principais pontos a ser observado pelo novo diploma é a necessidade do consentimento. Até então, dados pessoais eram coletados e tratados sem que o titular tivesse qualquer tipo de informação a este respeito. Agora, as empresas deverão requerer o consentimento do titular de forma expressa, com cláusula em destaque quando fornecido por escrito. $\mathrm{O}$ consentimento também poderá ser proporcionalizado de outro modo, desde que demonstre a manifestação de vontade do titular. Deverá ser definido a finalidade da coleta de dados e a que se destinam. Se as informações tiverem destinação de compartilhamento com terceiros, necessitará haver um consentimento adicional. Do mesmo modo, para o tratamento dos dados considerados sensíveis deverá haver consentimento de forma específica e destacada, para finalidades específicas. ${ }^{8}$

Contudo, o artigo $7^{\circ}$, da Lei 13.709, dispõe algumas situações nas quais os dados poderão ser tratados mesmo sem o consentimento do titular. Exemplificando, encontram-se nesse artigo a necessidade de tratamento para cumprimento de obrigação legal ou regulatória pelo controlador; para estudos por órgão de pesquisa, sendo que neste caso, sempre que possível, deverá haver a anonimização; proteção da vida ou da incolumidade física do titular ou de terceiros, assim como a tutela da saúde e a proteção do crédito.

Devido ao princípio do livre acesso, o titular terá ingresso facilitado aos seus dados, que deverão ser apresentados de forma clara, adequada e ostensiva. O titular ainda terá o direito de saber qual a finalidade; sua forma e duração do acesso aos dados; quem é o controlador; se as informações foram compartilhadas e qual a finalidade.

5 Inciso IV, artigo $4^{-0}$, Lei $13.709 / 18$

6 Inciso III, artigo $5^{\circ}$, Lei 13.709/18

7 Vide artigo $5^{\circ}$ e incisos da Lei $13.709 / 18$

8 Lei $13.709 / 18$, artigo 11, inciso I 
A LGPD, nos artigos 17 e 18, ainda confere outros direitos ao titular atendendo sempre os direitos fundamentais de liberdade, intimidade e privacidade. Desse modo, qualquer indivíduo poderá, mediante requisição ao controlador, saber se existe o tratamento de seus dados; acessálos; corrigir informações incompletas, inexatas ou desatualizadas; anonimização, bloqueio ou eliminação de dados desnecessários, excessivos ou tratados em desconformidade com o disposto nesta Lei ${ }^{9}$; requerer a portabilidade dos dados a outra empresa; eliminar dados pessoais tratados; informação das entidades com as quais os dados foram compartilhados; conhecimento sobre a consequência de não fornecer o consentimento; e revogar o consentimento.

Como pôde ser visto, neste breve apanhado da Lei, a LGPD, vem a alterar a forma como as informações armazenadas por empresas públicas ou privadas estão sendo tratadas. Essa dinâmica deverá ser alterada de forma significativa, conferindo ao titular maior acesso e transparência. Deve-se recordar que a aludida legislação, traz como exceção ao consentimento o tratamento de dados para a proteção do crédito $^{10}$. Com relação ao mercado financeiro, questiona-se se esse setor seria impactado com a nova Lei.

\title{
3 A LGPD NO SETOR BANCÁRIO: O QUE MUDA PARA O TOMADOR DE CRÉDITO?
}

\subsection{Concessão do crédito através do sistema de credit scoring}

A concessão de crédito é feita conforme uma análise de risco. Através da captura de dados, as instituições financeiras formam um cadastro e, de acordo com uma fórmula estatística atribuem uma nota ao cliente. Quanto maior a nota, menor risco para a instituição o cliente representa. Neste sentido, temos a definição de Vicente (2001, p.49) para "Credit score":

\begin{abstract}
Credit score pode ser definido como o processo de atribuição de pontos às variáveis de decisão de crédito mediante aplicação de técnicas-estatísticas. Trata-se de processo que define a probabilidade de que um cliente com certas características, pertença ou não a um grupo possuidor de outras determinadas características, consideradas desejáveis (hipótese em que se aprova um limite de crédito) ficando a critério da instituição dar alçada operacional ou não para o gestor atribuir o crédito. Esta técnica estabelece uma regra de discriminação de um determinado cliente solicitante de crédito.
\end{abstract}

Os autores Santos e Famá consideram que 'Para a composição dessa fórmula, os Bancos selecionam as principais informações cadastrais dos clientes e, em seguida, atribuem-lhes pesos ou ponderações de acordo com a importância destacada em suas políticas internas de crédito" (SANTOS; FAMÁ, 2007, p. 108). Esse sistema chamado de credit scoring é muito utilizado pelas instituições financeiras. Ele tem por objetivo uma minoração de riscos para as empresas de crédito, que tendo conhecimento sobre o perfil do pretenso cliente poderá ou não conceder o crédito ou deverá calcular com que base de juros irá transacionar com esse indivíduo. Apesar de um sistema institucionalizado, acaba trabalhando de forma discriminatória, pelo fato de que se uma pessoa representa um pequeno risco, outra irá representar um grande risco. Neste sentido, Mendes (2014, p.112) expõe que:

Além disso, o sistema de avaliação tem como finalidade dimensionar os riscos de contratação, indicando quais consumidores apresentam 'menos risco' de inadimplência. Como é de se esperar, a identificação dos melhores também pressupõe a identificação daqueles considerados os 'piores consumidores'. Esses são aqueles para quem as empresas têm interesse de oferecer as piores ofertas ou nenhuma oferta. Ademais, esses podem ter

9 Lei 13.709/18, artigo 18 , inciso IV 10 Lei $13.709 / 18$, artigo $7^{\circ}$, inciso X 
o seu acesso a bens e serviços negado, em razão da sua classificação como um consumidor "ruim".

O uso desse sistema implica que pessoas com menor capacidade creditícia tenham acesso somente a produtos muito ruins de crédito, arcando com altas taxas e um período de tempo de adimplemento diminuto, o que inviabiliza o acesso ao crédito à camada da população que mais necessita desse tipo de serviço, inclusive para fomentar o empreendedorismo de baixa renda.

\subsection{A Legislação Brasileira e o credit scoring}

A Legislação brasileira já vem se preocupando com os direitos do tomador de crédito. Além de outros, dois importantes dispositivos já regulam a formulação da avaliação e concessão do crédito no Brasil: O Código de Defesa de Consumidor; e a Lei no 12.414/ 2011, Lei do Cadastro Positivo. Esses instrumentos serviram de base para que o Relator do Recurso Especial no 1.419.697 - RS (2013/0386285-o), Ministro Paulo de Tarso Sanseverino, chegasse à conclusão sobre a licitude do sistema de atribuição de pontos ao tomador de crédito, o credit scoring. $\mathrm{O}$ Ministro atribuiu aos artigos $5^{\circ}$, IV e $7^{\circ}$, I, da Lei n. 12.414/2011 (Lei do cadastro positivo), a autorização da prática do credit scoring. No entanto, ponderou seu uso baseado nas diretrizes do Código de Defesa do Consumidor.

As teses firmadas no referido acórdão vislumbraram não só a licitude do credit scoring, como também que:

Na avaliação do risco de crédito, devem ser respeitados os limites estabelecidos pelo sistema de proteção do consumidor no sentido da tutela da privacidade e da máxima transparência nas relações negociais, conforme previsão do CDC e da Lei n. 12.414/2011. Apesar de desnecessário o consentimento do consumidor consultado, devem ser a ele fornecidos esclarecimentos, caso solicitados, acerca das fontes dos dados considerados (histórico de crédito), bem como as informações pessoais valoradas.

O desrespeito aos limites legais na utilização do sistema "credit scoring", configurando abuso no exercício desse direito (art. $187 \mathrm{do} C \mathrm{C}$ ), pode ensejar a responsabilidade objetiva e solidária do fornecedor do serviço, do responsável pelo banco de dados, da fonte e do consulente (art. 16 da Lei n. 12.414/2011) pela ocorrência de danos morais nas hipóteses de

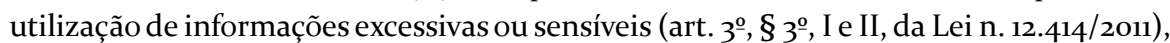
bem como nos casos de comprovada recusa indevida de crédito pelo uso de dados incorretos ou desatualizados.

Citando o artigo 43, do Código de Defesa do Consumidor e a Lei do Cadastro Positivo, o relator auferiu que não há proibição sobre os arquivos de consumo. Contudo, vislumbrou que antes da Lei 12.414/11, os cadastros continham somente informações negativas, não contemplando o bom pagador.

Nos últimos anos, esses cadastros de registros de informações negativas passaram a ser questionados pelo mercado de consumo, pois, sinalizando apenas o mau pagador, não valorizam o bom consumidor, que cumpre corretamente as suas obrigações. (Resp. no 1.419.697 - RS- 2013/0386285-o, p.18)

Com o advento da Lei do Cadastro Positivo, passou a ser possível a formação e a consulta a bancos de dados com informações de adimplemento. Se antes as informações se compunham de dados sobre dívidas não pagas, agora conterão também, "outras informações que possam exprimir dados positivos sobre a sua capacidade financeira e o seu histórico de 
adimplemento" (BIONI, 2019). Isso desde que haja autorização prévia do "potencial cadastrado mediante consentimento informado por meio de assinatura em instrumento específico ou em cláusula apartada". ${ }^{11}$

Todavia, a Lei 12.414/11, assegura como direito do cadastrado "conhecer os principais elementos e critérios considerados para a análise de risco, resguardado o segredo empresarial;" "solicitar ao consulente a revisão de decisão realizada exclusivamente por meios automatizados; e ter os seus dados pessoais utilizados somente de acordo com a finalidade para a qual eles foram coletados." ${ }^{12}$

Ressalta-se a Súmula 550, do Superior Tribunal de Justiça que aduz:

A utilização de escore de crédito, método estatístico de avaliação de risco que não constitui banco de dados, dispensa o consentimento do consumidor, que terá o direito de solicitar esclarecimentos sobre as informações pessoais valoradas e as fontes dos dados considerados no respectivo cálculo.

Mesmo que o credit scoring não seja considerado um banco de dados, o órgão superior não retirou do tomador de crédito a possibilidade de solicitar informações constantes desses cadastros.

Contudo, existe uma diferença básica do banco de dados a que se refere a Lei 12.414/11, com credit scoring que habitualmente as instituições financeiras utilizam. A principal diferença está na questão que no primeiro caso, o cliente consentiu que seus dados de adimplemento fossem manipulados e expostos, enquanto no segundo o cliente sequer sabe que suas informações foram passadas por um tratamento específico para gerar uma determinada pontuação.

\subsection{O Sistema do Credit Scoring, Dados Sensíveis e a LGPD}

Sabe-se que, o credit scoring não é considerado um instrumento ilícito na concessão do crédito; que a súmula 550, do STJ, aduz que tampouco seja um banco de dados e; que existem algumas legislações pertinentes ao tema. Podemos, portanto, questionar se com o advento da LGPD, em 2018, haveria um encalço para as instituições financeiras.

A primeira questão é posicionar o cadastro de credit scoring na legislação que trata da proteção dos dados pessoais.

Note-se que a própria LGPD contempla o termo "crédito"13 em seu conteúdo. Isto demonstra que, apesar de haver especificidades sobre o assunto, ele (credit scoring) não se isenta da legislação. Veja-se o $§ 6^{\circ}$, do artigo $7^{\circ}$, que diz que "A eventual dispensa da exigência do consentimento não desobriga os agentes de tratamento das demais obrigações previstas nesta Lei, especialmente da observância dos princípios gerais e da garantia dos direitos do titular." Nas palavras de Frazão (2018, p. 2-3) "[...] fica claro que os casos de dispensa de consentimento não têm qualquer repercussão sobre os demais direitos dos titulares de dados, os quais continuam igualmente exigíveis."

Outro interessante dispositivo da Lei se encontra no artigo 12, que trata da anonimização. $\mathrm{O}$ §2º, do referido artigo aduz que: "Poderão ser igualmente considerados como dados pessoais, para os fins desta Lei, aqueles utilizados para formação do perfil comportamental de determinada pessoa natural, se identificada." Este paragrafo diz respeito às possíveis informações obtidas através de dados anonimizados que, em conjunto, acabam

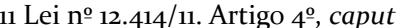

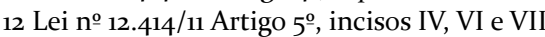

13 Lei 13.709/18. Artigo $7^{\mathbf{0}}$, inciso X; artigo 20, caput; 
formando o perfil de uma pessoa, quando reconhecida. Muitas vezes se trata de dados sensíveis provenientes de dados "inofensivos".

Frazão (2018, p. 2-3), também dita que:

É importante destacar que, por meio da inteligência artificial, cada vez mais é possível inferir dados sensíveis a partir de dados não sensíveis, relacionados a interações no mundo real ou no mundo virtual - as chamadas «pegadas digitais» -, sendo tais inferências utilizadas para a classificação das pessoas em determinados perfis. Por essa razão, o § $2^{\circ}$, do art. 12, da LGPD, já mencionado quando se tratou da anonimização (Parte II), contém importantíssima previsão segundo a qual «Poderão ser igualmente considerados como dados pessoais, para os fins desta Lei, aqueles utilizados para formação do perfil comportamental de determinada pessoa natural, se identificada.

Para a composição do credit scoring, as empresas agrupam informações como profissão; idade; estado em que nasceu; cidade em que reside; sexo; grau de instrução; estado civil; tipo de residência; tempo em que reside em sua residência atual; indicador de registro no CCF (Cadastro de Cheques sem Fundo) nos últimos 3 anos; indicador de registro do cônjuge no CCF nos últimos 3 anos; tempo de abertura da conta (em meses); tipo da conta; situação do cartão de crédito do correntista na instituição (Correia e Machado, 2004), que podem ser utilizados para se chegar na pontuação acima mencionada.

Note-se que, de acordo com Lei 13.709/18, a maior parte desses dados são os chamados dados pessoais ${ }^{14}$, não chegando a poder classificá-los como dados sensíveis. Contudo, informações mais específicas poderão ser classificadas como dados sensíveis.

Segundo Bioni (2019) e outros autores, dados que parecem inofensivos, "triviais", após determinado tratamento, podem se transformar em um dado sensível. Sendo assim, simples informações podem identificar individualidades como orientação sexual e raça. ${ }^{15}$

A formação de um cadastro que tem por objetivo a concessão de crédito, normalmente, se dá por um sistema utilizado para o tratamento dos dados através de uma fórmula automatizada, na qual serão os algoritmos que irão concluir a capacidade creditícia do sujeito (MONTEIRO, 2018). Isso representa uma vantagem às instituições, uma vez que, "as decisões são feitas de forma consistente de acordo com um critério pré-estabelecido a um baixo custo, porque são processadas por um computador e não através do julgamento humano" (VICENTE, 2001). Esse tipo de manipulação de dados, muitas vezes, exclui a ação humana e, os agentes envolvidos (gerente/cliente) não possuem acesso à fórmula utilizada para se determinar a nota alcançada. Desta forma, pode também haver transformações de dados simples em dados sensíveis.

Mendes (2014), cita que:

(...) é fundamental proteger também outros dados que, embora aparentemente insignificantes, podem vir a se tornar sensíveis, a depender do tipo de tratamento sensível dos dados, que é capaz de transformar dados inofensivos em informações potencialmente discriminatórias.

Recorda-se que, sendo possível a manipulação de dados, esta não poderá ser discriminatória e uma das características dos dados sensíveis é o fator discriminação (BIONI, 2019).

14 Lei 13.709/18, artigo 5o, inciso I.

15 Ainda que, assim como um dado anônimo pode se tornar um dado pessoal, um dado "trivial" pode também se transmudar em um dado sensível; particularmente, quando se têm disponíveis tecnologias (e.g. Big Data) que permitem correlacionar uma série de dados para prever comportamentos e acontecimentos, tal como ocorreu em uma loja de departamentos que identificou quais consumidoras estariam grávidas, precisando, inclusive, o período gestacional. É possível, portanto, identificar individualidades mais sensíveis das pessoas, tais como orientação sexual, raça e estado de saúde, a partir de informações triviais. 


\subsection{Os dados automatizados na formação do credit scoring}

Neste ponto, a Lei 13.709/18 poderá influenciar as instituições financeiras. O artigo 20, da referida Lei, dispõe que:

O titular dos dados tem direito a solicitar a revisão de decisões tomadas unicamente com base em tratamento automatizado de dados pessoais que afetem seus interesses, incluídas as decisões destinadas a definir o seu perfil pessoal, profissional, de consumo e de crédito ou os aspectos de sua personalidade.

Apesar de lícito e permitido o credit scoring, o tratamento de dados para a proteção do crédito $^{16}$, segundo o artigo 20, será possível mediante o acesso à informação contida no banco de dados.

Monteiro (2018, p.10) esclarece que:

Já o artigo 20 da LGPD garante o direito de solicitar a revisão, por um ser humano, de uma decisão tomada unicamente com base em tratamento automatizado. O objetivo é evitar que indivíduos sejam alvo de práticas discriminatórias dos algoritmos responsáveis pela decisão. Todavia, não é qualquer decisão totalmente automatizada que pode ser alvo de uma revisão humana: somente as que afetam os interesses dos titulares dos dados pessoais, o que inclui, mas não se limita, àquelas utilizadas para definir perfis comportamentais de cunho pessoal, profissional, de consumo e de crédito.

O princípio da transparência previsto no inciso VI, do artigo 6º, da LGPD, vigora, também, quanto aos dados informatizados do credit score, possibilitando ao indivíduo, que teve suas informações tratadas, esclarecimento sobre os critérios adotados para chegar a tal pontuação.

Ainda Monteiro (2018, p.11), esclarece:

Em síntese, a LGPD garante aos indivíduos o direito a ter acesso a informações sobre que tipos de dados pessoais seus são utilizados para alimentar algoritmos responsáveis por decisões automatizadas. Caso o processo automatizado tenha por finalidade formar perfis comportamentais ou se valha de um perfil comportamental para tomar uma decisão subsequente essa previsão também incluirá o acesso aos dados anonimizados utilizados para enriquecer tais perfis. Esse direito ainda inclui a possibilidade de conhecer os critérios utilizados para tomar a decisão automatizada e de solicitar a revisão da decisão por um ser humano quando esta afetar os interesses dos titulares.

As informações pertinentes ao cliente deverão ser fornecidas pelo controlador de forma clara e adequada. Todavia, a Lei ressalva segredos comercial e industrial. ${ }^{17}$ Como não há um dispositivo que aufere o que seriam segredos comercial e industrial, será necessário o estudo caso a caso (MONTEIRO, 2018, p.14). Se não forem concedidas as informações, e sendo observados os segredos comercial e industrial, poderá haver uma auditoria da autoridade nacional para a verificação de aspectos discriminatórios no tratamento dos dados automatizados. ${ }^{18}$ Ressalta-se que, a defesa dos titulares deverá ser exercida por ação individual ou coletiva (MINISTÉRIO DA JUSTIÇA, 2016, p.194).

Outro importante ponto a ser debatido está no conteúdo do artigo 21 que diz que "Os dados pessoais referentes ao exercício regular de direitos pelo titular não podem ser utilizados em seu prejuízo." Resta analisar se este dispositivo impediria o tratamento de dados para a concessão do crédito quando a pontuação se mostrar insuficiente, impedindo a obtenção do

16 Lei $13.709 / 18$. Artigo $7^{\circ}, \mathrm{X}$.

17 Lei 13.709/18. Artigo 20, § $1^{\circ}$

18 Lei 13.709/18. Artigo 20, § 2o. 
empréstimo. Durante os debates do anteprojeto, propostas avulsas sugeriram sua eliminação justamente com o argumento do limite de crédito:

\begin{abstract}
(A). A lei não deve criar uma vedação ao uso de dados pessoais em prejuízo do titular voltada a dados obtidos legalmente. "O disposto no art. 20, que veda o uso de dados em prejuízo do titular, quando referentes ao exercício regular de direitos, é bastante vago e, por isso, permite interpretações imprecisas. Ao praticar atividades financeiras, por exemplo, o cidadão exerce regularmente seus direitos. No entanto, isso não deveria impedir uma instituição bancária de, com base em tais dados, definir um limite de crédito para o titular dos dados" [Brasscom] "Sugere-se a eliminação do artigo. Tal como o artigo 19, este artigo dispõe sobre uma ingerência desproporcional do estado nas relações contratuais e lesão ao direito de liberdade de contratar". [Vivo] Autores da proposta: Brasscom, Vivo e ABDTIC (MINISTÉRIO DA JUSTIÇA, 2016, p.194)..
\end{abstract}

Todavia, o artigo foi mantido, restando às interpretações auferir sobre sua incidência ou não com relação ao credit scoring

\title{
3.5 Direito ao "apagamento" "Direito de ser esquecido" Direito à eliminação dos dados pessoais
}

Outras benesses da Lei para o tomador de crédito estão contidas nos artigos 17 e 18, quanto aos direitos dos titulares, além de ser assegurada a titularidade de seus dados pessoais e garantidos os direitos fundamentais de liberdade, de intimidade e de privacidade. O titular poderá, através de requerimento, obter acesso aos seus dados e corrigi-los; ter acesso à anonimização, ao bloqueio ou à eliminação de dados desnecessários, excessivos ou tratados em desconformidade com o disposto nesta Lei; requerer a portabilidade para outro fornecedor; conseguir a eliminação dos dados pessoais tratados com o consentimento do titular, exceto nas hipóteses previstas no art. 16 desta Lei; dentre outros, ter o direito de revogação do consentimento ${ }^{19}$.

O regulamento europeu de proteção de dados pessoais (GDPR) expõe, expressamente, o "Direito ao apagamento de seus dados" e entre parênteses "direito de ser esquecido"º . Embora, ainda não pacificado pela doutrina internacional, a natureza do direito ao esquecimento contido no artigo $17^{\circ}$, da GDPR, se obteria com a conotação de right of oblivion ou de right of erasure (Belay, s/d), pois este dispositivo possibilita que dados sejam apagados das plataformas digitais. Não são todos os casos que propiciam esse direito ao apagamento. Nesse sentido, a definição de Reding (2010, p.4) reflete bem o espírito do artigo.

Equally, this could include strengthening the so-called 'right to be forgotten', ie the right of individuals to have their data fully removed when they are no longer needed for the purposes for which they were collected or when he or she withdraws consent or when the storage period consented to has expired.

A autora, em poucas palavras, coloca três situações nas quais os dados poderiam ser apagados: quando as informações não forem mais necessárias para o propósito em que foram coletadas; quando se retira o consentimento; e quando o período de armazenamento consentido expirou. O artigo $17^{\circ}$, do GDPR é mais extenso e expõe outras possibilidades como a retirada dos dados tratados de forma ilícita ${ }^{21}$.

19 Lei 13.709/18. Artigo 18

20 GDPR. Artigo 17

21 GDPR. Artigo 17, Inciso "d" 
A Lei nacional LGPD, não contempla de forma expressa o direito ao apagamento ou direito ao esquecimento. Todavia, como referido anteriormente, os artigos 17 e 18, da lei brasileira trazem alguns direitos do titular e, entre eles, bloqueio e eliminação de dados desnecessários ${ }^{22}$. Não há dúvida quanto à definição de "bloqueio" e "eliminação" na Lei 13.709/18, já que a própria lei os define nos incisos XIII e XIV, do artigo $5^{0.23}$ Mesmo não havendo um direito ao apagamento na Lei nacional é de grande força o dispositivo que trata do bloqueio e eliminação dos dados pessoais. Nesse contexto, Frazão (2018) observa que:

(...) o inciso VI do art. 18, da LGPD, reforça, como direito dos titulares de dados, a "eliminação dos dados pessoais tratados com o consentimento do titular, exceto nas hipóteses previstas no art. 16 desta Lei.” Ao assim fazer, deixa claro que, nos casos de consentimento, a eliminação dos dados tanto na hipótese de revogação do consentimento, como na hipótese do término do prazo de tratamento de dados, é medida ainda mais indispensável.

Com relação ao tratamento de dados para a análise de crédito, existiria uma exceção, já que se trata de uma das possibilidades de tratamento de dados sem a necessidade do consentimento. Mas isso não retira do titular o direito de opor-se quando há descumprimento do disposto na Lei, assim como alude o $§ 2^{\circ}$, do artigo $18^{24}$. Devido ao direito de eliminação de informações desnecessárias, todos aqueles dados excessivos poderão ser revistos e eliminados. "As instituições financeiras podem manter alguns dados para garantir a conformidade com outros regulamentos, mas em todas as outras circunstâncias em que não há justificativa válida, o direito do indivíduo de ser esquecido se aplica” (Equipe Reamp., 2018).

\section{CONSIDERAÇÕES FINAIS}

A lei 13.709/18, LGPD, que tem por propósito a proteção do titular dos dados pessoais, entrará em vigência em 2020. As empresas que lidam com tratamento de dados pessoais, independentemente, de sua área de atuação, deverão se adequar à nova legislação. Tal situação não objetiva somente atender às novas disposições, como também se ajustar aos moldes das legislações internacionais, pertinentes ao assunto, quando há interesse no trato comercial.

O crédito, como um dos importantes instrumentos de giro da economia, tem encontrado segurança para sua concessão, no sistema de credit scoring, sendo uma espécie de coleta e armazenamento de dados que tem por finalidade auferir a capacidade de adimplência de determinado solicitante. Esse sistema, normalmente automatizado, através da manipulação de algoritmos e uma série de tabelas estatísticas, aufere uma nota ou pontos ao pretenso tomador de crédito. $\mathrm{O}$ fato de ser um sistema altamente automatizado o torna obscuro, impossibilitando às pessoas envolvidas a compreensão tanto dos dados implicados como a fórmula utilizada para que fosse auferida a pontuação em si.

Pode ocorrer de um solicitante, mesmo que pessoa idônea e sem dívidas na praça, possuir uma pontuação demasiada baixa e, assim, ter sua pretensão negada ou uma taxa de juros acima do habitual impossibilitando o empréstimo em questão. Apesar de haver algumas legislações regulando o assunto, até o momento, o sistema de scoring tem ficado velado nas instituições financeiras.

22 Lei 13.709/18. Artigo 18, inciso VI

23 Lei 13.709/18. Artigo 5ำ, incisos XIII e XIV - "XIII - bloqueio: suspensão temporária de qualquer operação de tratamento, mediante guarda do dado pessoal ou do banco de dados; XIV - eliminação: exclusão de dado ou de conjunto de dados armazenados em banco de dados, independentemente do procedimento empregado.

24 Lei 13.709/18. Artigo 18, § 2. O titular pode opor-se a tratamento realizado com fundamento em uma das hipóteses de dispensa de consentimento, em caso de descumprimento ao disposto nesta Lei. 
Foi constatado que o Superior Tribunal de Justiça entendeu que o sistema de credit scoring é lícito no país. E após a promulgação da Lei do Cadastro Positivo, foi permitido o uso de informações positivas no cadastro com finalidade de concessão de crédito. Atualmente é necessário o consentimento do titular para constar nos cadastros positivos, apesar de haver em tramitação uma alteração da referida lei passando do opt-in para o opt-out, ou seja, todos constariam automaticamente do cadastro e quem não quisesse deveria requerer sua saída.

No presente, as instituições financeiras trabalham tanto com o cadastro positivo quanto com o credit scoring habitual (contendo informações negativas). Com o advento da LGPD, algumas observações deverão ser consideradas pelas instituições que trabalham com crédito.

O principal impacto da LGPD será sentido por outras estruturas que trabalham com tratamento de dados pessoais, sendo que poucos aspectos influenciarão a estrutura do setor de crédito.

A lei possibilita o tratamento de dados pessoais para a concessão do crédito, mas não quanto aos dados sensíveis. As poucas alterações a serem observadas serão quanto aos dados sensíveis e a automação dos cálculos para chegar a determinada pontuação. Como no caso do credit scoring as decisões acabam sendo tomadas através de uma formulação totalmente automatizada. Sendo assim, o titular poderá requerer sua revisão e o controlador deverá fornecer "informações claras e adequadas a respeito dos critérios e dos procedimentos utilizados para a decisão automatizada." ${ }^{25}$. O parágrafo ressalva os segredos comercial e industrial, embora não especifique o que viria a ser esses segredos. Dados desnecessários, excessivos, tratados em desconformidade com a lei, inexatos e sensíveis poderão ser bloqueados ou apagados. No mais, algo ainda nebuloso é o conteúdo do artigo 21, com relação ao credit scoring, que observa que "os dados pessoais referentes ao exercício regular de direitos pelo titular não podem ser utilizados em seu prejuízo." Neste ponto, acredita-se ser necessário estender o debate, se tal dispositivo impediria a utilização de dados obtidos legalmente para a negativa da concessão do crédito.

Sublinha-se que, mesmo que se entenda necessário que as instituições financeiras devem se revestir da maior segurança possível para a concessão do crédito, o setor público poderá sempre se esforçar por uma maior transparência, tanto dos dados constantes quanto da fórmula adotada no credit scoring. A Lei não deve isentar as instituições de apresentar a formulação utilizada para se chegar ao score em questão com base nos segredos comercial e industrial. Esse aspecto deverá ser elucidado e posto às claras no que significa, exatamente, "segredo comercial e industrial" no tratamento de dados pessoais, uma vez que, a obscuridade e a opacidade no credit scoring pode esconder interesses ilegítimos, tais como aqueles que levaram à crise imobiliária de 2008 (Paschoale, 2015, p.102), nos Estados Unidos e outros países. A formulação deve ser manipulada de modo a aferir o interesse de poucos contra muitos. Destarte, ressalta-se ser imprescindível a transparência dos meios altamente automatizados.

\section{REFERÊNCIAS}

BELAY, Raquel C. M. Direito ao Esquecimento e o Regulamento Geral Sobre a Proteção de Dados Pessoais: Entre Garantias e Ameaça à Liberdade de Expressão. Disponível em: bibliotecadigital.fgv.br/ojs/index.php/rpdue/article/download/68238/65864. Acesso em: 17 jan.2020.

BIONI, Bruno Ricardo. Proteção de Dados Pessoais: a função e os limites do consentimento. Editora Forense, Rio de Janeiro. 2019. E book Kindle.

25 Lei 13.709/18. Artigo 20, § 1은 
BRASIL. MINISTÉRIO DA JUSTIÇA. O que está em jogo no debate sobre dados pessais no Brasil? Relatório final sobre o debate público promovido pelo Ministério da Justiça sobre o anteprojeto de lei de proteção de dados pessoais. Disponível em: http://www. internetlab.org.br/wp-ontent/uploads/2016/o5/reportaapl._dadospessoais_final.pdf. Acesso em 19 jan.2020.

CORRÊA, Marcelo França; MACHADO, Maria Augusta Soares. Construção de um Modelo de Credit Scoring Baseado em Redes Neurais para Previsão de Inadimplência na Concessão de Micro-Crédito. Artigo. Disponível em: http://www.anpad.org.br/admin/pdf/ enanpad2004-fin-o884.pdf. Acesso em: 14 jan.2020.

DONEDA, Danilo. Da Privacidade à Proteção de Dados Pessoais. Capítulo 1. Disponível em: http://renatoleitemonteiro.com.br/wp-content/uploads/2016/o9/Danilo-Doneda-Daprivacidade-a-protecao-de-dados.pdf. Acesso em: 14 jan.2020.

EQUIPE REAMP. Como a LGPD afeta o departamento financeiro? Publicado no dia 31 de outubro de 2018. Disponível em: http://reamp.com.br/blog/2018/10/como-a-lgpd-afeta-odepartamento-financeiro/ Acesso em: 14 jan.2020.

FRAZÃO, Ana. A nova Lei Geral de Proteção de Dados Repercussões para a atividade empresarial: o tratamento dos dados pessoais sensíveis e o tratamento dos dados de crianças e adolescentes Parte VI. Disponível em: https://www.jota.info/opiniao-e-analise/ colunas/constituicaoempresa-e-mercado/nova-lgpd-tratamento-dos-dados-de-criancaseadolescentes-03102018. Acesso em: Acesso em: 17 jan.2020.

FRAZÃO, Ana. Nova LGPD: as demais hipóteses de tratamento de dados pessoais. A quarta parte de uma série sobre as repercussões para a atividade empresarial. Disponível em: https://www.jota.info/opiniao-e-analise/artigos/nova-lgpd-as-demais-hipoteses-detratamento-de-dados-pessoais-19092018. Acesso em: 17 jan.2020.

FRAZÃO, Ana. A nova Lei Geral de Proteção de Dados Pessoais. Principais repercussões para a atividade empresarial: direito de anonimização, bloqueio ou eliminação de dados. Parte X. Disponível em: http://anafrazao.com.br/files/publicacoes/2018-10-31-A_nova_Lei_Geral_ de_Protecao_de_Dados_Pessoais_Principais_repercussoes_para_a_atividade_empresarial_ direito_de_anonimizacao_bloqueio_ou_eliminacao_de_dados_Parte_X.pdf. Acesso em: 17 jan. 2020.

MENDES, Laura Schertel. Privacidade, proteção de dados e defesa do consumidor: linhas gerais de um direito fundamental, São Paulo, Saraiva, 2014.

MONTEIRO, Renato Leite. Existe um direito à explicação na Lei Geral de Proteção de Dados do Brasil? Instituto Igarapé. Artigo Estratégico 39. Dezembro, 2018. Disponível em: https://igarape.org.br/wp-content/uploads/2018/12/Existe-um-direito-a-explicacao-na-LeiGeral-de-Protecao-de-Dados-no-Brasil.pdf. Acesso em: 12 jan. 2020.

OECD Guidelines on the Protection of Privacy and Transborder Flows of Personal Data. Disponível em: http://www.oecd.org/internet/ieconomy/ 
oecdguidelinesontheprotectionofprivacyandtransborderflowsofpersonaldata.htm. Acesso em: 26 jan.2020.

O GLOBO MUNDO. Matriz da Cambridge Analytica participou de mais de 200 eleições, diz delator. De 22/03/2018. Disponível em: https://oglobo.globo.com/mundo/matriz-dacambridge-analytica-participou-de-mais-de-200-eleicoes-diz-delator-22515244. Acesso em: 12 jan. 2020.

PASQUALE, Frank. The Black Box Society: The Secret Algorithms That Control Money and Information. Harvard University Press. Cambridge Massachussets. London England. 2015. Disponível em: https://doc.lagout.org/science/o_Computer\%2oScience/2_Algorithms/ The\%2oBlack\%2oBox\%2oSociety_\%2oThe\%2oSecret\%2oAlgorithms\%2othat\%2oControl\%2o Money\%2oand\%2oInformation\%20\%5BPasquale\%202015-01-05\%5D.pdf. Acesso em: 13 jan.2020.

REDING, Viviane. Tomorrow's Privacy. PDF. Artigo. International Data Privacy Law, 2011, Vol. 1, No. 1. 17 de novembro de 2010. Disponível em: https://doi.org/10.1093/idpl/ipqoo7. Acesso em: 17 jan.2020.

SANTOS, José Odálio dos; FAMÁ, Rubens. Avaliação da aplicabilidade de um modelo de credit scoring com varíaveis sistêmicas e não-sistêmicas em carteiras de crédito bancário rotativo de pessoas físicas. Rev. contab. finanç. vol.18 no.44 São Paulo May/Aug. 2007. Print version ISSN 1519-7077On-line version ISSN 1808-057X. Disponível em: http:// www.scielo.br/scielo.php?script=sci_arttext\&pid=S1519-70772007000200009\&lang=pt. Acesso em: 13 jan. 2020.

SIMÃO FILHO, Adalberto; SCHWARTZ, Germano André Doederlin. Big Data Big Problema! O Paradoxo entre o Direito à Privacidade e o Crescimento Sustentável. IV Encontro Internacional do Compedi. (4. : 2016 : Oñati, ES), Disponível em: http://www.indexlaw.org/ index.php/conpedireview/article/view/3644. Acesso em: 12/01/2019

STJ. Recurso Especial. № 1.419.697 - RS (2013/o386285-o). Relator: Ministro Paulo de Tarso Sanseverino. Disponível em: https://bdjur.stj.jus.br/jspui/bitstream/2011/114173/Julgado_2.pdf. Acesso em: 13 jan.2020.

UNIÃO EUROPEIA. Parlamento Europeu e Conselho da União Europeia. Regulamento 2016/679 de 27 de abril de 2016. Relativo à proteção das pessoas singulares no que diz respeito ao tratamento de dados pessoais e à livre circulação desses dados e que revoga a Diretiva 95/46/ CE (Regulamento Geral sobre a Proteção de Dados). Publicações da União Europeia. Disponível em: https://eur-lex.europa.eu/legal-content/PT/TXT/PDF/?uri=CELEX:32016Ro679\&from=pt. Acesso em 11 jan.2020.

VICENTE. Ernesto F. R. A estimativa do risco na constituição da PDD. Dissertação de Mestrado, USP. São Paulo: maio/20o1. Disponível em: http://www.teses.usp.br/teses/ disponiveis/12/12136/tde-31012002-000545/pt-br.php. Acesso em: 15 jan.2020. 